\title{
The New England Deposit Library
}

As assistant librarian in charge of the catalog department at the Harvard College Library, Mr. Osborn has observed the need for storage facilities in and around Boston and has been in close touch with the deposit library project as it has developed.

$\mathrm{T}$

HE New england Deposit Library, which is situated in the part of Boston known as Allston, was opened March 2, 1942. Its first librarian was Robert L. Work, who is now in the Navy. Construction was started in July I94I, so that, while priorities affected the building in several major respects and in many matters of detail, contracts were in general filled reasonably well.

It was indeed fortunate that the deposit library was available for use shortly after the outset of the war, for it has relieved some of the overcrowding in the cooperating libraries at a time when conditions of work made such relief doubly desirable. At Harvard, for example, the Army or Navy has taken over a number of buildings containing libraries or has occupied space in a library in such a way that the books had to be shifted at very short notice. Many of the books that were affected have been stored in the deposit library, though most of them will not remain there after the end of the war. The business and law school libraries are two of the departmental libraries which have sent some of their material to make room for the service training program. An entire collection was sent to the deposit library when the Freshman Union was taken over by the Navy. The union had housed the Modern Language Center, where there were several thousand books and periodicals, chiefly recent French and German material. These books are now stored for the duration and can be brought back whenever they are needed again. Accommodation has been found similarly for the libraries that some of the faculty members, called into government or war service, had in their offices and studies.

Without the deposit library to care for such items, the library staff at Harvard would have had to contend with grave problems of storage. The main library would have been called upon to assume much of the burden at a time when it was already critically crowded. Such a situation would probably have meant that the books would have remained boxed up for the duration, whereas now they can be shelved, serviced, and cared for properly in the deposit library.

Not all the material stored to meet war exigencies has been books. When the Navy took over dormitories at the Harvard Business School and installed doubledecker beds, the single beds were stored on one level of the deposit library which had not yet been shelved. These beds have since been removed for use, but their place has been taken by furniture belonging to the Fogg Art Museum.

Even before the building was officially opened it was called on to serve a war 
function, for in January 1942 it became the headquarters of the regional Victory Book Campaign. For eighteen months victory books were received, stored, sorted, and sent out from the deposit library, the basement and one other floor being given over to the campaign. This summer the victory books were removed to the Boston Public Library because of the difficulty of getting volunteer help to Allston without the use of automobiles.

The Army has occupied the first stack level for a year, utilizing the space for research laboratories. Since the stacks were windowless, the Army asked for and was granted permission to construct windows on this level; it has also put in a door to provide a separate outside entrance to its quarters. These windows and the door will presumably be removed at the end of the war.

\section{The Building and Its Equipment}

The design of the building is simplicity itself, for the whole structure is severely utilitarian. The structure is little more than a brick shell, eighty-eight by sixtyfour feet, surrounding an inexpensive type of stack with six levels. The floors for each level are of reinforced concrete with supporting pillars. All the space is given over to shelving except for a five-foot center aisle. The only windows in the bookstack are at the ends of this aisle, both front and rear. Three quarters of the shelving provided is for books, the rest for newspapers. Between the book ranges the aisles are twenty-six inches wide and between the newspaper ranges, thirty inches. Due to war conditions, only one level could be built with steel. Wooden shelves have been provided for the other floors. The lumber has been cut and the uprights installed, but the shelves are put in place only when there is need for them. The wooden shelves are not quite as satisfactory as steel would have been, but they serve very well. A fire-resistant paint was used on them.

Both the steel and the wooden shelving are adjustable, but only with difficulty. This is one reason why the shelves are not inserted until there is need for them. At that time the carpenter can fix the wooden shelves at the required heights. In these circumstances allowance has to be made for the fact that the shelves on both sides of a double range have to be set at exactly the same height. The wooden shelves are supported by cleats which take away a certain amount of the height at each end. Fixed shelves of this type, like the narrow aisles, are a handicap in the first shelving of books. Thereafter this disadvantage tends to disappear, since use of the shelves is slight and the books will not be moved from one location to another.

In front of the bookstack there is a unit consisting of a reading room, shipping room, and work rooms. This unit is only one story in height, with the work rooms occupying the basement. The reading room has accommodation for twenty readers, which is likely to prove ample for a very considerable time. The shipping room could well have been larger for the initial shipments. Congestion there, however, has been due in no small measure to the very large quantities of victory books that kept arriving along with material being regularly deposited.

The building is not air conditioned but has forced ventilation. Foresight was displayed in the installation of a convertible oil or coal furnace. Oil was used until conversion became necessary under wartime conditions, and then the system was changed to coal. The capacity is sufficient 
to take care of the second unit when that is erected.

There is space for approximately eight hundred thousand books plus a considerable number of newspapers. At the rate the building is being filled up, a second unit will be required within the next five years. This new unit may well have a number of features which were not considered desirable when the present building was planned. New features may include special provision for nonbook materials, certain gift collections which must be held together as units, etc.

The present unit cost $\$ 2$ I 2,500 for the building and its equipment, including the shelving on five floors. If building costs do not increase greatly, a second unit, which would not need a reading room, shipping room, or heating unit, could be built for about $\$ \mathbf{1} 75,000$. Each cooperating library rents a certain amount of space. The rental charge for a section eight feet, three inches in height is $\$ 5.50$ per annum or twenty cents a foot. This is enough to take care of all charges, which include interest and amortization, maintenance, and service. If two thirds of the building is rented, and more than that is already, there is a surplus which may be used to pay off the mortgage more rapidly, to reduce the rent paid by the cooperating libraries, or to lay aside to help build a new unit.

\section{Shelving the Books}

Each cooperating library is responsible for shipping and shelving its own material and also for filing its cards in the deposit library catalog. The procedure in each library is to select books suitable for deposit, change whatever records may be necessary (making an extra card for the deposit library if need be), pack the books in boxes that are provided by the deposit library, arrange for transportation, and then unpack and shelve the books. A truckload consists of about fifty boxes, and it has been found that eight to ten boxes can be packed in an hour. Newspapers are shipped without being boxed. Since March 1942 Harvard College Library has maintained a steady schedule on this basis. Other libraries have shipped material as the occasion arose.

Five of the cooperating libraries have adopted a classification by size, adding a running number to the classmark which designates the height of a book. The following is the classification which Harvard College Library, Massachusetts Institute of Technology, and Simmons College are using. The Boston Athenaeum and Tufts have used exactly the same classification, only substituting the letters "AT" or "TU" for "K." The classification is as follows :

$\mathrm{KC}$ up to and including $67_{8}^{\prime \prime}$

KD over $67^{\prime \prime}$ and up to $78^{\prime \prime}$

KE over $78^{\prime \prime}$ and up to $878^{\prime \prime}$

KF over $88^{\prime \prime}$ and up to $98^{7 \prime}$

$\mathrm{KG}$ over $97^{\prime \prime}$ and up to $\mathrm{I} \mathrm{I}_{8}^{7}$

KH over II ${ }^{7 \prime \prime}$ and up to $138^{7 \prime}$

$\mathrm{KJ}$ over $138^{7 \prime}$ and up to $19^{\prime \prime}$

KN newspapers and books over $19^{\prime \prime}$

KPC-KPJ poor paper, etc.

KSC-KSJ incomplete serials

The measurements will probably be adjusted when a new unit with steel shelving is erected. This classification was arrived at simply by figuring the distance there would be between shelves if, for example, ten shelves were to be used to a section.

With a number of the classes there might be several inches of waste space in each section if it contained only books belonging to one class. Actually no wastage occurs, for larger books have been put on the bottom shelf wherever such a situa- 
tion arose. Shelving devices of all kinds abound, including vertical and horizontal ribboning. No attempt has been made to keep whole classes of books together or whole runs of serials, unless they happen to be deposited at the same time. A detailed stack directory enables classes to be located readily, even though they are broken up into several parts. In the case of newspapers, where no classification has been used and where the titles were not shipped in alphabetical order, the directory gives the location of each title. Very large newspapers have been shelved in the end sections on the center aisle. They are turned sidewise so that the titles can be read from the center aisle. Some books in end sections have been piled on their sides, so that their titles can be read from the center aisle. This gives greater shelving capacity, thus making a virtue of a disadvantage arising from the use of wooden shelves.

The initial shelving of books is more difficult than would be the case in regular bookstacks. One factor is the narrowness of the aisles between ranges; another is a consequence of the economical methods of preparing the books for the deposit library, which result in most of the books having no location symbol on the spine. This, coupled with the fact that the lessexperienced help used to pack or unpack the books frequently gets the books considerably out of order, makes the initial shelving a relatively slow process.

Once material regularly deposited has been shelved, the intention is that it will not be shifted from one location to another. When later units of the deposit library are erected, some shift of materials may well be desirable in order, for example, to concentrate the holdings of a particular library or to bring together scattered parts of a class. Apart from such considerations, the general theory is that space will be steadily and systematically occupied throughout an entire unit until that unit is completely full and that there will be no general shift of material such as must take place in ordinary bookstacks from time to time.

\section{Simplified Cataloging at Harvard}

For more than two years Harvard College Library has been cataloging books from its current accessions to be sent directly to the deposit library. It is still too early to state what proportion of the current accessions can be treated in this manner, but the figure might well be in the vicinity of 20 per cent. Practically all this material falls in the class of littleused books. Recently, however, the whole archives of the Massachusetts W.P.A. were sent directly to the deposit library, thus saving many problems of cataloging and handling.

Simplified cataloging has been adopted for books which are originally cataloged for the deposit library. This results in cutting the cost of cataloging at least in half for such material. Somewhat less attention is given to the establishing of authors' names for these books, but the title page is transcribed exactly as it would be for other material. The entire collation is omitted except for the statement of volumes and the series note. The only notes that are used are those which are essential for the identification of a book. Added entries and subjects are omitted if other editions are already in Harvard College Library. If no other edition is present, added entries are made where necessary and subject headings within limits. When there are many editions of a book already in Harvard College Li- 
brary, cards are omitted from the public catalog for the copies in the deposit library. Instead, a general -reference card is filed under the author referring the reader to the official catalog for a full statement of the library's holdings. As this particular practice grows, it has in a small way the effect of weeding the card catalog in much the same way that the shelves are being weeded.

Economies are also practiced in preparing the books for the shelves. No binding or repairing is done for books going to the deposit library. Unbound books are bundled when paper covers are too light or when the condition of the book calls for some strengthening. Books with loose bindings are firmly tied. The saving in binding costs alone has already run into - several thousand dollars.

Book tags are placed on every tenth volume instead of on each book. The tag goes on each book whose running number ends in a zero. In the case of long sets every tenth volume, regardless of its running number, is tagged.

\section{Types of Material}

Four of the cooperating libraries have not yet deposited any material. They are Boston College, Boston University, Massachusetts Historical Society, and Radcliffe College. The material deposited by the other cooperating libraries may briefly be characterized as follows:

Boston Athenaeum: Films, newspapers, photostats, and a long run of large accession books

Boston Public Library: Newspapers

Harvard College Library: Books, newspapers, and serials

Harvard Graduate School of Business Administration: Newspapers and an extensive collection of business manuscripts
Harvard Graduate School of Engineering: Serials

Harvard Law School: Books and law reports

Massachusetts Institute of Technology: Books, encyclopedias, and serials

Massachusetts State Library: Newspapers and duplicate holdings of Massachusetts documents

Simmons College: Books

Tufts College: Books

So far there has been astonishingly little duplication of titles deposited. It may be found that the cooperating libraries are sufficiently varied so that what is little used in one institution may be in demand in another. Thus Massachusetts Institute of Technology has deposited a set of the Preussische Jahrbücher, which would be indispensable in Harvard College Library. On the other hand, Harvard has deposited a set of United States Patent Specifications which Massachusetts Institute of Technology undoubtedly would not do. Since most of the material deposited is available to any of the cooperating libraries, a beneficial result of such deposits may well be that in many cases libraries will be able to utilize the deposited items as muchneeded second copies in reserve.

The practice followed at Harvard in selecting material from the stacks for transfer to the deposit library has been to choose material where little or no record work would be involved. Whole classes were taken first; then serials where a shelf or more could be sent at a time; lastly, sets such as Gibbon's Decline and Fall of the Roman Empire, of which thirty-seven sets were sent to the deposit library while fifteen were kept in Harvard College Library. After this material has been exhausted, the process will become more expensive, as more record work will then have to be done. 


\section{Use of the Deposit Library}

In the first eighteen months that the deposit library was open, fifty-three readers used books and newspapers on the spot. Six of these readers were sent there from the Boston Public Library, four from the Harvard Graduate School of Business Administration, three from the Boston Athenaeum; the remainder came from Harvard College Library, which has by far the largest amount of material on deposit. Readers who go directly to the deposit library must have an introduction from a cooperating library. They have mostly gone to work with newspapers, serials, or encyclopedias. In the case of newspapers, readers are generally expected to go to the deposit library instead of having the volumes returned for use in the cooperating library. Serials and encyclopedias, like books, can be made available within twenty-four hours at any of the cooperating libraries, but occasionally it is better for a reader to go to the deposit library when he has a fairly extensive amount of material to consult. This was the case with one reader from Harvard who wanted to compare the first nine editions of the Encyclopaedia Britannica.

In the first eighteen months of operation a total of 652 titles was circulated, including eighty newspapers. This figure includes use in the building and books sent out to the cooperating libraries. By far the greatest use is made of serials and newspapers. Next come directories and encyclopedias, followed by fiction and juvenile literature. The same book is seldom called for twice.

All charges are being preserved, since they will undoubtedly serve as the basis for making many studies of reader interest in little-used books. From such a point of view the deposit library should prove to be a laboratory where much useful information can be derived concerning matters such as the life span of books and the desirability of cooperative acquisition and storage for various types of books.

\section{Duties of the Librarian}

Since the librarian of the deposit library may have no other assistant than a janitor, he obviously has to be a jack of all trades. As regards incoming material, his responsibility is to allocate the necessary space and give advice when that is desired. He must maintain the stack directory so that he can begin to service the material once it has been shelved. He must be exceedingly versatile, for there is no telling what may be shipped to him next. On one occasion a truck drew up at the door with a twentyton art object which was supposed to be stored in the deposit library. The driver expected help from the library staff in unloading his truck, but a glance at the tremendous object showed that there was no way of getting it into the library, so the librarian had to see that arrangements were made to have it stored elsewhere.

One of the duties of the librarian which has not yet been called into play but which is expected to develop appreciably in the course of time, is the handling of duplicate copies deposited by two or more libraries. If, for example, both Harvard College Library and Simmons deposit their back files of the Publishers' Trade List Annual, it is more than likely that one of the sets can and should be discarded. The plan is for the librarian to study the duplicate sets and recommend to the libraries concerned that one set be discarded and that the other then become the property of the : deposit library for the continuing use of all interested parties.

New developments are proved by time, 
and the deposit library has established its value in a comparatively short period. The most valuable material it contains is undoubtedly the serials and newspapers, and here steady but relatively small use may be expected. It is clear that littleused books can be selected reasonably well from the holdings and accessions of reference libraries, to be preserved for the occa- when doubtful cases have arisen.

With the deposit library now a going and successful concern, thoughts can soon be turned towards developing it still further. Among ideas that may be considered are the following: (I) Harvard College Library has sent its entire collection of textbooks, which is one of the very best in the country, to the deposit library.

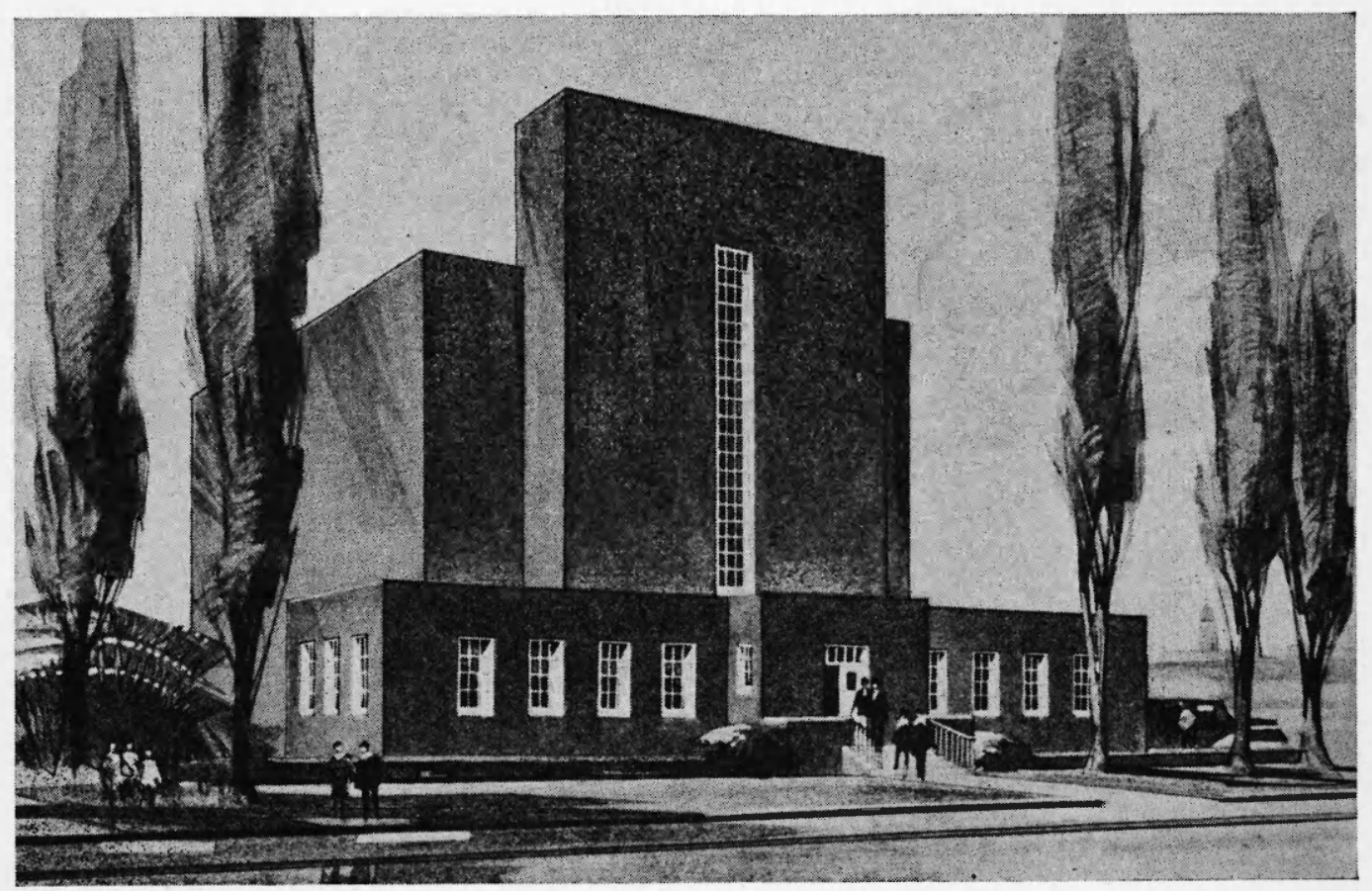

New England Deposit Library

sional use of the historian and the bibliographer for the most part.

Bookstacks have been improved by judicious weeding, overcrowding in the stacks has been reduced or eliminated for the time, processing costs have been decreased, and reference service has been but slightly inconvenienced. Part of the success of the scheme undoubtedly has been due to wise selection of material to be deposited and to considerate treatment
Should other libraries in the region consider sending elementary and secondary textbooks there in order to make one magnificent joint collection? (2) Many of the popular public libraries have littleused books which should not be simply sold or destroyed and whose removal would make these libraries into better working collections. Should state governments be approached to provide funds for such little-used books as are worth preserving to 
be stored in the deposit library? (3) Some of the public libraries and other smaller institutions have rarities which they cannot preserve properly or which they must house in buildings that are not fireproof. Again it might be desirable to obtain state funds for the proper preservation of such material in a unit of the deposit library specially constructed to take care of a limited number of rare books. With the wholesale destruction of cultural objects in Europe, increased responsibility falls on the shoulders of Americans to see that rare and valuable material in libraries here is properly preserved. Here is one means by which rarities could be safeguarded for smaller institutions and yet be made available to them for use when needed.

\section{References}

Massachusetts. Laws, Statutes, etc. "An Act to Incorporate New England Deposit Library and Regulating the Operation of Said Library and Authorizing Certain Libraries to Make Use of Its Facilities." (In Massachusetts. General Court. Acts and Resolves, 194I, chapter 240.)

Metcalf, Keyes D. "The New England Deposit Library." Library Quarterly I2:622-28, July 1942.

Osborn, Andrew D. "Books for the Deposit Library." Harvard University Library Notes 4:80-83, March 1942.

Work, R. L. "New England Deposit Library." Library Journal 67:358, April I942.

By. HAROLD L. LEUPP

\section{Storage of Little-Used Library Materials}

$M r$. Leupp is librarian of the University of California Library, Berkeley.

$\mathrm{D}$ ESPITE theoretical objections to division of the collections, in the cold light of financial and other practical considerations the storage method of dealing with accumulations of little-used materials in a large library certainly has its points. The principal difficulties involved, no one of which seems necessarily insurmountable, appear to be about as follows:

(I) Difficulty of selecting material to be stored
To comb out the collections title by title would be a formidable undertaking. Records of use would not help much, since the unrecorded use of certain materials is extensive and important. Very large libraries probably will include considerable groups of little-used material, transfer of which to storage would be not only a relatively simple matter but would release a maximum of shelf space with slight expenditure of time and labor. But even Harvard, with its four million volumes, according to my information, plans to store only three hundred thousand, or 